\title{
DUKUNGAN KELUARGA DENGAN UPAYA MEMINIMALISIR SERANGAN STROKE PENDERITA HIPERTENSI DI WILAYAH KERJA PUSKESMAS BONTONYELENG KECAMATAN GATTARENG
}

${ }^{1}$ Aszrul $A B$

${ }^{2}$ Andi Suswani

\footnotetext{
${ }^{1}$ Departemen Keperawatan Keluarga dan Komunitas Stikes Panrita Husada Bulukumba

${ }^{2}$ Departemen Keperawatan Keluarga dan Komunitas Stikes Panrita Husada Bulukumba
}

\section{Alamat Korespondensi:}

Ns.A.Suswani M,S.Kep,S.KM,M.Kes

Program Studi Ilmu Keperawatan

Sekolah Tinggi Ilmu Kesehatan Panrita Husada

Bulukumba, 04132514721

HP: 085255001632

Email:aderialmakmur@yahoo.co.id 


\begin{abstract}
ABSTRAK
Dukungan keluarga sangat penting diberikan bagi penderita stroke atau yang mengalami kejadian stroke. Dukungan keluarga diberikan sebagai bentuk usaha kesehatan. Secara garis besar usaha kesehatan dibagi menjadi tiga yaitu usaha preventif (pencegahan), usaha kuratif (pengobatan), dan usaha rehabilitasi (Maulana, 2014: 38). Artinya bahwa dalam upaya meminimalisir serangan stroke pada penderita hipertensi maka keluarga harus memberikan dukungan kepada penderita hipertensi agar melakukan perubahan pola hidup. Tujuan penelitian ini adalah untuk mengetahui hubungan antara dukungan keluarga terhadap upaya meminimalisir serangan stroke pada penderita hipertensi di Wilayah Kerja Puskesmas Bontonyeleng Kecamatan Gantarang Kabupaten Bulukumba. Penelitian ini menggunakan desain penelitian kuantitatif dengan menggunakan desain korelasi deskriptif. Sampel penelitian ini sebanyak 50 yang diambil dengan metode total sampling yaitu keseluruhan populasi dijadikan sebagai sampel penelitian. Analisis data dalam penelitian ini menggunakan uji statistik uji Chi Square. Berdasarkan hasil penelitian didapatkan dukungan keluarga paling banyak responden terdapat pada kategori baik sebanyak 29 responden (58\%), sedangkan upaya keluarga dalam meminimalisir serangan stroke pada penderita hipertensi paling banyak terdapat pada kategori tidak melakukan sebanyak 33 responden (66\%). Hasil analisis menggunakan uji statistik Chi Square didapatkan nilai $p$ adalah 0,000, dengan demikian $p<\alpha(0,000<0,05)$. Kesimpulan dari penelitian ini adalah terdapat Hubungan Antara Dukungan Keluarga Terhadap Upaya Meminimalisir Serangan Stroke Pada Penderita Hipertensi Di Wilayah Kerja Puskesmas Bontonyeleng Kecamatan Gantarang Kabupaten Bulukumba. Saran dari penelitian ini adalah dapat menambah informasi dan masukan bagi petugas kesehatan agar dapat meningkatkan upaya pemulihan bagi penderita hipertensi tentang pentingnya dukungan keluarga dengan upaya keluarga dalam meminimalisir serangan stroke pada penderita hipertensi.
\end{abstract}

Kata Kunci: dukungan keluarga, hipertensi, stroke

\begin{abstract}
Family support is very important for stroke patients or those who experience a stroke. Family support is given to health care. Broadly speaking, health efforts are divided into three prevention, curative prevention and rehabilitation efforts (Maulana, 2014: 38). Successfully preventing stroke in patients with hypertension, the family must provide support for patients with hypertension so that lifestyle changes.The purpose of this study was to study the relationship between family support for efforts to prevent stroke in hypertensive patients in the Bontonyeleng Public Health Center Gantarang District, Bulukumba Regency.This study uses quantitative research design using descriptive design. The sample of this study amounted to 50 people taken by the total sampling method that is all participants who were used as the study sample. Data analysis in this study used the Chi Square test statistic test.Based on the results of the research obtained by the respondents, there were mostly in the good category as many as 29 respondents (58\%), while the family efforts in minimizing stroke in hypertensive patients were mostly found in the non-done category as many as 33 respondents (66\%). The results of the analysis using the Chi Square statistical test obtained a p value of 0,000, thus $p<\alpha(0,000<0,05)$. The conclusion of this study is about the relationship between families with efforts to minimize stroke in hypertensive patients in the work area of Bontonyeleng Public Health Center, Gantarang District, Bulukumba Regency. Suggestions from this study are to be able to add information and input for health workers to be able to increase assistance for hypertensive patients regarding family needs with family prevention in minimizing stroke in patients with hypertension.
\end{abstract}

\title{
Keywords: Family Support, Stroke, Hypertension
}


PENDAHULUAN

Stroke didefinisikan sebagai gangguan saraf permanen akibat terganggunya peredaran darah ke otak, yang terjadi sekitar 24 jam atau lebih. (Lingga, 2013:1). Stroke merupakan peringkat kedua penyebab kematian dengan laju mortalitas 18\% - 37\%. Angka kejadian stroke adalah 200 per 100.000 penduduk dalam satu tahun, diantara 100.000 penduduk maka 800 orang akan menderita stroke. (Pudiastuti, 2011).

Data tentang angka kejadian stroke di dunia sangat beragam. Di Auckland, Selandia Baru insiden stroke pada kelompok usia 55-64 tahun ialah 20 per 10.000 penduduk dan di soderhamn, Pada kelompok usia di atas 85 tahun dijumpai insiden stroke dari 184 per 10.000 di Rochester, Minnesota, dan 397 per 10.000 penduduk di Soderham, swedia. Fieschi dalam Jumraini (2013:9). Masih dari sumber yang sama data tentang insiden stroke di Amerika Serikat 270 per 100.000 pada pria dan 201 per 100.000 pada wanita. Di Inggris insiden stroke 174 per 100.000 pada pria dan 233 per 100.000 pada wanita.

Berdasarkan hasil riset kesehatan dasar tahun 2013 (RISKESDAS 2013) stroke merupakan penyebab kematian utama di Indonesia. Prevalansi stroke di Indonesia berdasarkan diagnosis tenaga kesehatan sebesar 7,0 per mil dan berdasarkan diagnosis tenaga kesehatan atau gejala sebesar 12,1 per mil. Jadi, sebaganyak $57,9 \%$ penyakit stroke telah terdiagnosis oleh nakes.

Prevalansi stroke berdasarkan diagnosis nakes dan gejala tertinggi terdapat di Sulawesi Selatan (17,9\%o), DI Yogyakarta (16,9\%), Sulawesi Tengah (16,6\%o), di ikuti jawa timur sebesar 16 per mil. Kecenderungan prevalansi stroke berdasarkan wawancara menunjukkan kenaikan dari 8,3 per mil pada tahun 2007 menjadi 12,1 per mil pada tahun 2013 (Riskesdas 2013).

Terdapat $67,6 \%$ kasus stroke di Sulawesi Selatan yang telah didiagnosis oleh tenaga kesehatan, prevalansi tertinggi dijumpai di kabupaten wajo 13,6\% dan terendah di Kabupaten Pangkaje'ne Kepulauan 2.9\%. Berdasarkan data surbvailans penyakit tidak menular bidang P2PL dinas kesehatan provinsi Sulawesi selatan tahun 2013 bahwa terdapat stroke penderita lama sebanyak 823 kasus dan penderita baru sebanyak 2.061 kasus (Dinas Kesehatan Provinsi Sulawesi Selatan 2014).

Sementara data pasien stroke di Kabupaten Bulukumba menurut data dari RSUD H. A. Sulthan Dg. Radja pada tahun 2015 sebanyak 78 orang. Meskipun mengalami penurunan dari tahun sebelumnya (2014) yaitu sebanyak 95 
orang. Angka tersebut masih terbilang tinggi dan perlu penanganan serius.

Untuk melakukan pencegahan terhadap serangan stroke maka sangat penting untuk mengetahui faktor risiko stroke. Faktor risiko kejadian stroke disebabkan banyak faktor, salah satunya adalah hipertensi. Menurut Lingga (2013) "Salah satu faktor risiko terjadinya stroke adalah hipertensi. sekitar $40-90 \%$ stroke dialami oleh penderita hipertensi. Artinya adalah hipertensi adalah kondisi yang sangat rawan terhadap terjadinya serangan stroke."

Menurut data dari World Health Organization (WHO) tahun 2012 sekitar $26,4 \%$ penduduk dunia menderita hipertensi dan diperkirakan akan meningkat menjadi $29,2 \%$ pada tahun 2025. Selain itu, hipertensi juga merupakan penyakit penyebab kematian peringkat keempat belas dengan prosentase $1,7 \%$ dan diprediksi akan meningkat menjadi $2,1 \%$ atau peringkat delapan pada tahun 2030 .

Tujuan umum dari penelitian ini adalah diketahuinya hubungan antara dukungan keluarga terhadap upaya meminimalisir serangan stroke pada penderita hipertensi di Wilayah Kerja Puskesmas Bontonyeleng Kecamatan Gantarang Kabupaten Bulukumba

\section{METODE}

Penelitian ini merupakan penelitian kuantitatif desain observasional analitik dengan pendekatan Case Control

Populasi adalah Keseluruhan objek penelitian atau objek yang diteliti adalah populasi (Notoatmodjo, 2010). Populasi dalam penelitian ini adalah semua penderita hipertensi yang berada pada Wilayah Kerja Puskesmas Bontonyeleng Kecamatan Gantarang Kabupaten Bulukumba pada tahun 2016 dan rata-rata tiap bulannya yang berjumlah 50 pasien.

Sampel merupakan bagian dari populasi yang akan diteliti atau sebagian jumlah dari karakteristik yang dimiliki oleh populasi. Penarikan sampel menggunakan teknik total sampling yaitu keseluruhan populasi dijadikan sebagai sampel penelitian (Sugiyono, 2012)

Alat pengumpulan data dirancang oleh peneliti sesuai dengan kerangka konsep yang telah dibuat. dukungan keluarga. Dukungan informasi berisi 5 pernyataan, dukungan penghargaan berisi 5 pernyataan, dan dukungan emosional berisi 5 pernyataan. Jadi, kuesioner yang diberikan totalnya berisi 15 pertanyaan.

Data dianalisis berdasarkan skala ukur dan tujuan penelitian dengan menggunakan perangkat lunak program komputerisasi. Data dianalisis secara : (1). Analisis Univariat, Analisis dilakukan untuk melihat proporsi. (2). Analisis 
Bivariat, Uji bivariat dilakukan untuk mencari hubungan antara variabel independen dan variabel dependen dengan uji yang digunakan adalah chi-square bila memenuhi syarat, dan akan dilakukan uji gabung sel dan fisher's exact sebagai alternative. Interval kepercayaan yang diambil adalah $95 \%$ dan batas kemaknaan yang diterima apabila $\mathrm{p}<0,05$.

\section{HASIL}

Pada Tabel 1 hasil penelitian ini, berdasarkan dukungan keluarga paling banyak responden terdapat pada kategori baik sebanyak 29 responden (58\%), sedangkan dukungan keluarga pada kategori kurang sebanyak 21 responden (42\%).Penelitian ini sejalan dengan penelitian yang dilakukan oleh Elmiani et.al, (2014) bahwa dari 36 responden dapat diketahui jumlah dukungan keluarga dalam menjalankan diet hipertensi yaitu yang mendukung sebanyak 23 responden $(63,9 \%)$ dan yang tidak mendukung sebanyak 13 responden $(36,1 \%)$

Pada Tabel 2 hasil penelitian menujukkan distribusi jumlah responden berdasarkan upaya keluarga dalam meminimalisir serangan stroke pada penderita hipertensi paling banyak terdapat pada kategori tidak melakukan sebanyak 33 responden (66\%). Sedangkan upaya keluarga dalam meminimalisir serangan stroke pada penderita hipertensi pada $\begin{array}{lll}\text { kategori melakukan sebanyak } 17 & \end{array}$ responden (34\%).

Berdasarkan Tabel 3 hasil penelitian menujukkan responden yang dukungan keluarga baik dengan melakukan upaya meminimalisir stroke pada pasien hipertensi sebanyak 17 responden (34\%), sedangkan paling banyak responden yang dukungan keluarga kurang dengan tidak melakukan upaya meminimalisir stroke pada pasien hipertensi sebanyak 21 responden $(42 \%)$.

Hasil analisis dengan menggunakan uji Chi-Square diperoleh nilai significancy sebesar 0,000 ( $p<0,05)$, maka dapat disimpulkan bahwa "terdapat hubungan dukungan keluarga dengan upaya keluarga dalam meminimalisir serangan stroke pada penderita hipertensi Di Wilayah Kerja Puskesmas Bontonyeleng Kecamatan Gantarang Kabupaten Bulukumba"

\section{PEMBAHASAN}

Berdasarkan hasil penelitian dan uraian teori diatas salah satu faktor pendukung pasien taat dalam upaya meminimalisir stroke pada penderita hipertensi adalah dukungan keluarga, dimana dukungan ini berupa dukungan emsoional, materil serta psikis. Pada dasarnya dukungan keluarga dapat menjadi faktor yang sangat berpengaruh dalam menentukan keyakinan dan nilai kesehatan individu (lansia) serta dapat juga 
menemukan tentang program pengobatan yang dapat mereka terima. Keluarga dengan dukungan yang baik, tentunya akan selalu mengingatkan untuk meminum obat, mengatur pola makan dan pola tidurnya. Artinya bahwa dalam upaya meminimalisir serangan stroke pada penderita hipertensi maka keluarga harus memberikan dukungan kepada penderita hipertensi agar melakukan perubahan pola hidup, baik dengan pemberian dukungan berupa dukungan informasi terkait hipertensi dan serangan stroke, dukungan penghargaan serta dukungan emosi yaitu dengan memberikan perawatan dan palayanan terbaik kepada penderita hipertensi. Penelitian ini sejalan pula dengan penelitian Herlina yang menunjukkan bahwa dukungan keluarga sangat mempengaruhi perasaan dan motivasi lansia dalam mencegah terjadinya komplikasi pada keluarga yang menderita hipertensi."

\section{KESIMPULAN DAN SARAN}

Dukungan keluarga paling banyak responden terdapat pada kategori baik, karena keluarga mampu memberikan dukungan dan perhatian terutama dalam melaksanakan tugasnya terhadap lansia dengan cara menjaga dan merawat lansia serta memberikan perhatian sehingga lansia merasa dihargai dan meningkat status kesehatannya
Terdapat hubungan dukungan keluarga dengan upaya keluarga dalam meminimalisir serangan stroke pada penderita hipertensi Di Wilayah Kerja Puskesmas Bontonyeleng Kecamatan Gantarang Kabupaten Bulukumba

Hasil penelitian ini dapat menambah referensi perpustakaan dan wawasan mahasiswa Stikes Panrita Husada Bulukumba mengenai dukungan keluarga dengan upaya keluarga dalam meminimalisir serangan stroke pada penderita hipertensi. Dapat menambah informasi dan masukan bagi petugas kesehatan agar dapat meningkatkan upaya pemulihan bagi penderita hipertensi dan diharapkan juga akan memberikan manfaat kepada masyarakat dalam hal informasi tentang pentingnya dukungan keluarga dengan upaya keluarga dalam meminimalisir serangan stroke pada penderita hipertensi

\section{DAFTAR PUSTAKA}

Cassey, Aggie \& Benson, Hebbert. 2006. Menurunkan Tekanan Darah. Terjemahan oleh Nirmala Devi. PT. Buana Ilmu Populer. Jakarta

Lany, Gunawan. 2001. Hipertensi. Kanisius. Yogyakarta Lingga, lani. 2013. All About Stroke. Kelompok Gramedia. Jakarta 
Maulana, Nova. 2014. Sosiologi \& Antropologi Kesehatan. Nuha Medika. Yogyakarta

Pudiastuti, Ratna Dewi. 2011. Penyakit Pemicu Stroke. Nuha Medika. Yogyakarta Sudjana, Nana. 2013. Tuntunan Penyusunan Karya Ilmiah. Sinar Baru Algesindo. Bandung

Sugiharto, Aris. 2007. Faktor-faktor Risiko Hipertensi Grade II Pada Masyarakat, Vol

Sugiyono. 2012. Metode Penelitian Kombinasi. Alfabeta. Bandung

Suyanto. 2011. Metodologi dan Aplikasi Penelitian Keperawatan. Nuha Medika. Yogyakarta

Tamasse, Jumraini. 2013. Stroke dan Pencegahannya. Identitas Universitas Hasanuddin. Makassar Herlinah, L. (2013). Hubungan Dukungan Keluarga Dengan Perilaku Lansia Dalam Pengendalian Hipertensi, Persatuan Perawat Nasional Indonesia: Jurnal Keperawatan Komunitas, Vol 1 (2), Hal 114

Trianni, L. (2013). Hubungan antara tingkat pendidikan dan dukungan keluarga terhadap kepatuhan berobat pada penderita hipertensi di puskesmas ngaliyan semarang, Sekolah Tinggi Ilmu Keperawatan Telogorejo: Karya Ilmiah S1 Keperawatan, Vol 1 (3) Hal. 7.
Yenni. (2011). Hubungan dukungan keluarga dan karateristik lansia dengan kejadian stroke pada lansia hipertensi di wilayah kerja perkotaan bukittinggi. UNiversitas Indonesia. Jurnal Akademik UI Mekara Kesehatan. 
Tabel 1. Distribusi Jumlah Responden Berdasarkan Dukungan Keluarga Pada Penderita Hipertensi Di Wilayah Kerja Puskesmas Bontonyeleng Kecamatan Gantarang Kabupaten Bulukumba

\begin{tabular}{ccc}
\hline Dukungan Keluarga & Frekuensi & Persentase \\
\hline Baik & 29 & 58 \\
\hline Kurang & 21 & 42 \\
\hline Total & 50 & 100 \\
\hline
\end{tabular}

Tabel 2. Distribusi Jumlah Responden Berdasarkan Upaya Keluarga Dalam Meminimalisir Serangan Stroke Pada Penderita Hipertensi Pada Penderita Hipertensi Di Wilayah Kerja Puskesmas Bontonyeleng Kecamatan Gantarang Kabupaten Bulukumba

\begin{tabular}{ccc}
\hline Upaya Keluarga & Frekuensi & Persentase \\
\hline Melakukan & 17 & 34 \\
\hline Tidak Melakukan & 33 & 66 \\
\hline Total & 50 & 100 \\
\hline
\end{tabular}

Tabel 3. Analisis Hubungan Dukungan Keluarga Dengan Upaya Keluarga Dalam Meminimalisir Serangan Stroke Pada Penderita Hipertensi Pada Penderita Hipertensi Di Wilayah Kerja Puskesmas Bontonyeleng Kecamatan Gantarang Kabupaten Bulukumba

\begin{tabular}{|c|c|c|c|c|c|c|c|}
\hline & & \multicolumn{4}{|c|}{ Upaya Keluarga Meminimalisir Stroke } & \multirow{3}{*}{ Total } & \multirow{3}{*}{$p$} \\
\hline & & \multicolumn{2}{|c|}{ Melakukan } & \multicolumn{2}{|c|}{ Tidak Melakukan } & & \\
\hline & & $\mathrm{n}$ & $\%$ & $\mathrm{~N}$ & $\%$ & & \\
\hline \multirow{2}{*}{$\begin{array}{c}\text { Dukungan } \\
\text { Keluarga }\end{array}$} & Baik & 17 & 34 & 12 & 24 & 29 & 0,000 \\
\hline & Kurang & 0 & & 21 & 42 & & \\
\hline To & & 17 & 34 & 33 & 68 & 50 & \\
\hline
\end{tabular}

